JHR

36,4

\title{
Integrating maternal and child health data into the Iraqi Kurdistan health information system
}

756

Received 11 November 2020 Revised 14 February 2021 31 March 2021

Accepted 5 April 2021
Haveen H. Alsilefanee

Family Medicine, Duhok Directorate General of Health, Duhok, Iraq

Sivar A. Qadir

Directorate of Health, Sulaimani, Iraq

Shahla O. Salih

Department of Statistics and Informatics, University of Sulaimani, Sulaimani, Iraq

Luma H. Alhanabadi

Department Primary Health Care, Preventive Health Affairs Directorate, Duhok, Iraq, and

Leonardo Emberti Gialloreti and Stefania Moramarco

Biomedicine and Prevention, University of Rome Tor Vergata, Roma, Italy

\begin{abstract}
Purpose - The purpose of this study is to present the workflow on the integration of Maternal and Child Health Care Services (MCHCS) into the electronic Health Information System of the Iraqi Kurdistan (KRG-HIS). Design/methodology/approach - As part of the cooperation between the University of Rome Tor VergataItaly and the Iraqi Kurdistan Ministry of Health, six PhD positions were granted for Iraqi students to create a local team of experts with the aim of supporting the scaling-up of the KRG-HIS. After specific training, the team then trained the staff members of the health centers, met health authorities and analyzed the local scenario to ensure that the KRG-HIS could be better tailored to regional needs. In 2019, the integration of MCHCS into the KRG-HIS was one of the main areas of research.

Findings - Health data collection was mostly paper-based, which made vital statistics and evaluation of outcomes difficult to measure. More than 15,000 paper-files from the Duhok Obstetrics and Gynaecology Hospital were retrieved from storage. Then data entered in the KRG-HIS. Theoretical and practical training sessions were conducted for local staff members, with 183 health operators already having been trained. Daily supervision of the online system and field visits were ensured.

Originality/value - There is a need to support health authorities in improving data collection on MCHCS, ensuring the future self-sufficiency of the HIS. Key to the process is the creation of a specialized team of local experts with the objective of "training the trainers".
\end{abstract}

Keywords Maternal and child health, Epidemiological surveillance, Health information system,

Iraqi Kurdistan

Paper type Short report

(C) Haveen H. Alsilefanee, Sivar A. Qadir, Shahla O. Salih, Luma H. Alhanabadi, Leonardo Emberti Gialloreti and Stefania Moramarco. Published in Journal of Health Research. Published by Emerald Publishing Limited. This article is published under the Creative Commons Attribution (CC BY 4.0) licence. Anyone may reproduce, distribute, translate and create derivative works of this article (for both commercial and non-commercial purposes), subject to full attribution to the original publication and authors. The full terms of this licence may be seen at $h$ ttp://creativecommons.org/licences/by/4.0/legalcode

The author thanks the health personnel of the Iraqi Kurdistan Region-Duhok Province, who are actively and devotedly committed to collecting data.

Funding: The Italian Ministry of Foreign Affairs and International Cooperation (MAECI) and the Italian Agency for Development Cooperation (AICS) provided funding for this project. 


\section{Introduction}

Iraqi Kurdistan (KRI) is an autonomous region in the north of the country, subdivided into four governorates. The public health sector, administered by the KRI Ministry of Health $(\mathrm{MoH})$, delivers care at two levels: Public Hospitals (PHs) and Primary Health Care Centers (PHCCs) [1]. Maternal and Child Health Care Services (MCHCS) are present in many PHCCs and PHs providing care to women and offspring before and during pregnancy, as well as after childbirth. The health of women of reproductive age and under-five children is of special concern to KRI, since they account for nearly $40 \%$ of the total population [2]. Although some progress has been made in recent decades, women and children still face numerous health challenges, especially high mortality rates. More effort should therefore be put in place to complete the unfinished work of millennium goals [3].

With regard to vital health statistics, the Registration Bureaus for Birth and Deaths (RBBDs) in Kurdistan collect information from health facilities in each governorate. A networked system for timely sharing of information is not available, so the format, accuracy, completeness and accessibility of information are among the main challenges in the processing of data on country statistics.

To respond to this health priority, the University of Rome Tor Vergata-Italy and the KRI $\mathrm{MoH}$ - with the support of the Italian Agency for International Cooperation (AICS) - have been working together since 2015 to implement an electronic health information system in the region: the KRG-HIS. The system is based on the District Health Information Software 2 (DHIS-2) [4], an open-source Javascript-based platform that allows users to enter data directly from the periphery on the central servers, using only a web browser and even slow or discontinuous internet connections. The KRG-HIS was designed to manage public health data by collecting, analyzing and storing patients' medical records.

As part of the project, Iraqi personnel are being equipped on an ongoing basis with highly specialized knowledge so that they will be able to direct the entire process once the e-health system is under the management of the local authorities [5].

\section{Methodology}

We are presenting the workflow (Figure 1) and some preliminary findings of the $\mathrm{PhD}$ researchers aimed at scaling-up the KRG-HIS to gather MCHCS information in the Duhok Province.

Starting in 2018, the University of Rome Tor Vergata has granted six $\mathrm{PhD}$ positions (three in Public Health and Nursing Sciences and three in Computer Science Control and GeoInformation) to Iraqi students who already had a background in these specific fields. The students received ad hoc trainings on public health topics (i.e. surveillance systems and international health data coding), as well as on the operation and management of the DHIS-2 platform. A review of the scientific literature on the HIS availability and its implementation within the country was essential in setting up the evidence-based research.

The $\mathrm{PhD}$ students then collected information on the general structure of MCHCS (Duhok Province). Since some of the facilities dealing with MCHCS had already being integrated into the KRG-HIS, a preliminary analysis on data gathered was carried out. Further analysis was reserved for the Duhok Obstetrics and Gynaecology Hospital (DOGH), the only public maternity hospital in the city, which accounts for more than $40 \%$ of total births in the province every year.

Permission was obtained from the KRI health authorities to check health records, retrieve data from its storage systems, conduct meetings with MCHCS supervisors and focal persons, performing training for local staff members and monitor the sites. A hotline for the staff members of the health centers was set to provide a rapid question/answer mechanism. A list of additional centers to be integrated into the KRG-HIS was proposed. Tutors from the university designed and supervised the research, conducting onsite 
JHR
36,4

758

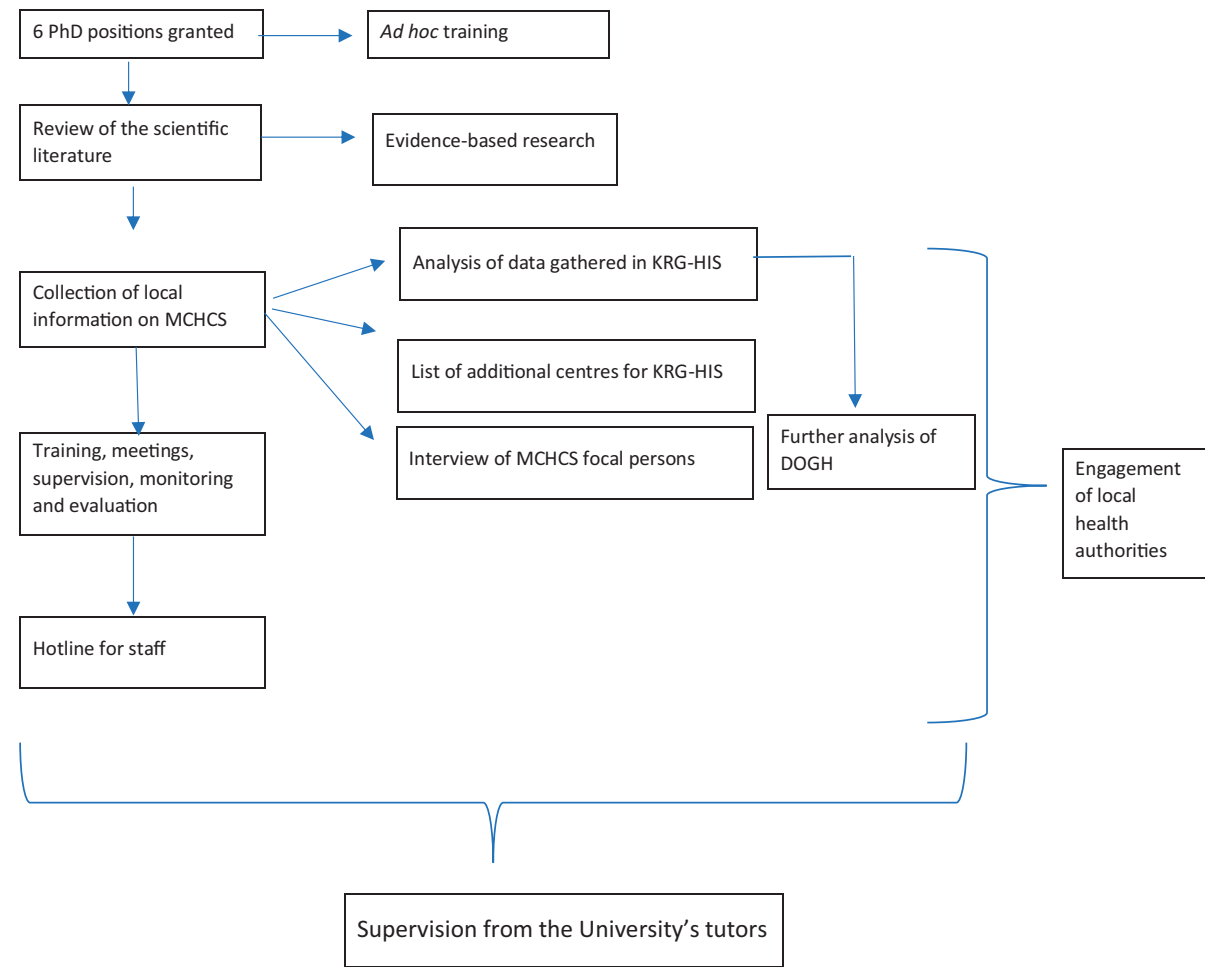

missions. Daily contacts with the $\mathrm{PhD}$ students were ensured by online meetings and using messaging tools.

\section{Ethical considerations}

The KRG-HIS was developed following the "WHO Guidelines on Ethical Issues in Public Health Surveillance" [6]. As the whole system is run in accordance with the national and regional legislation and institutional requirements, the institutional review board of the university waived at this stage any requirements for further ethical approval and written informed consent.

\section{Results}

Scientific literature review

Iraqi statistics indicate severe quality issues, with data completeness being classified as low [7]. The first assessment of registration systems was only requested by the World Health Organization (WHO) in 2012, and the evaluation showed a malfunctioning system, particularly in relation to the completeness of birth and death registrations. One of the WHO recommendations was to envisage the computerization of the system as the only way to produce accurate and consistent data [8]. When specifically referring to KRI, the available information is generally inferred from estimates based on patchy surveys' [9]. The consequence is a paucity of reliable health statistics and almost nonexistent epidemiological surveillance, with health policies often based on poor evidence [10] and health care quality not efficiently monitored or evaluated [11, 12]. 
Understanding gaps in MCHCS data collection

Data collection at the statistics departments is mainly paper-based with only a few offices using rudimentary computer programs for local data gathering. On a set date, aggregated data with rough analyses are sent to the statistics unit of the Directorate of Health, then all aggregated data are reported to the $\mathrm{MoH}$. Moreover, the fact that databases across the hospitals are not integrated represents a major obstacle in collecting and accessing information. When available data at RBBDs were specifically analyzed, the records were found to be scattered, with missing files or inaccurate/unavailable information. This generated a consistent risk of health statistics being incomplete and inaccurate.

\section{Interviewing MCHCS focal persons}

Networking with MCHCS supervisors and focal persons made it possible to identify and discuss the gaps in data entry (Table 1). As an example, they described how statisticians often report only minimal data about patients' discharge files to RBBDs, i.e. mainly diagnoses for the mother and/or the newborn, omitting many other important data such as gestational age, stillbirth, causes of death, child's gender.

\section{Data retrieval from $D O G H$ paper-based storage}

In January 2020, a further investigation was carried out on the DOGH's paper records kept in storage rooms. More than 15,000 old files were retrieved and analyzed, discovering nearly 200 missing files never been presented to the RBBD. At the same time, more than 260 instances of inaccurate/unavailable data were detected. The electronic input of these data in the KRG-HIS was planned for February 2020, along with routinely data entry (started in October 2019).

\section{Data gathering in the HIS}

Data entry into the KRG-HIS was proposed as a priority solution for better data collection and analysis. First, the staff members of the statistics department were given technical explanations about the e-health system. This covered theoretical and practical sections, including the International Classification of Diseases ICD-10, followed by the entry of health information into the system.

To date, the progressive scaling-up of the KRG-HIS within the Province of Duhok has already included 25 public health facilities (21 PHCCs, 4 PHs) recording more than 600,000 data items on MCHCS. The seven most common diagnoses observed in 2020 are shown in Table 2. The analysis of the data will be part of future findings for the $\mathrm{PhD}$ research.

\section{Engaging local health authorities}

Constant dialog and consultation with the KRI health authorities was ensured as part of the overall process. Performance gaps and proposals for implementation were discussed in order

\begin{tabular}{|c|c|c|c|c|c|c|c|}
\hline \multirow[b]{2}{*}{ Main gaps } & \multicolumn{2}{|c|}{ PHs (n.4) } & \multicolumn{2}{|c|}{$\begin{array}{c}\text { PHCCs } \\
\text { (n.21) }\end{array}$} & \multicolumn{2}{|c|}{$\begin{array}{c}\text { PHs and } \\
\text { PHCCS } \\
(\mathrm{n} .25)\end{array}$} & \\
\hline & $N$ & $\%$ & $N$ & $\%$ & $N$ & $\%$ & \\
\hline Data missing (e.g. stillbirth, causes of death) & 4 & 100 & 7 & 33 & 11 & 44.0 & \\
\hline Lack of human resources (i.e. working staff for data entry) & 2 & 50 & 9 & 43 & 11 & 44.0 & \\
\hline Poor equipment (e.g. computer, Internet access) & 1 & 25 & 9 & 43 & 10 & 40.0 & \\
\hline Poor supply (e.g. Internet rechargeable cards) & 1 & 25 & 9 & 43 & 10 & 40.0 & Table 1. \\
\hline Poor knowledge (e.g. training on data entry) & 1 & 25 & 11 & 52 & 12 & 48.0 & Main gaps identified \\
\hline Data management (e.g. data analysis) & 1 & 25 & 10 & 48 & 11 & 44.0 & within MCHCS \\
\hline
\end{tabular}

Maternal and child health data 
JHR

760

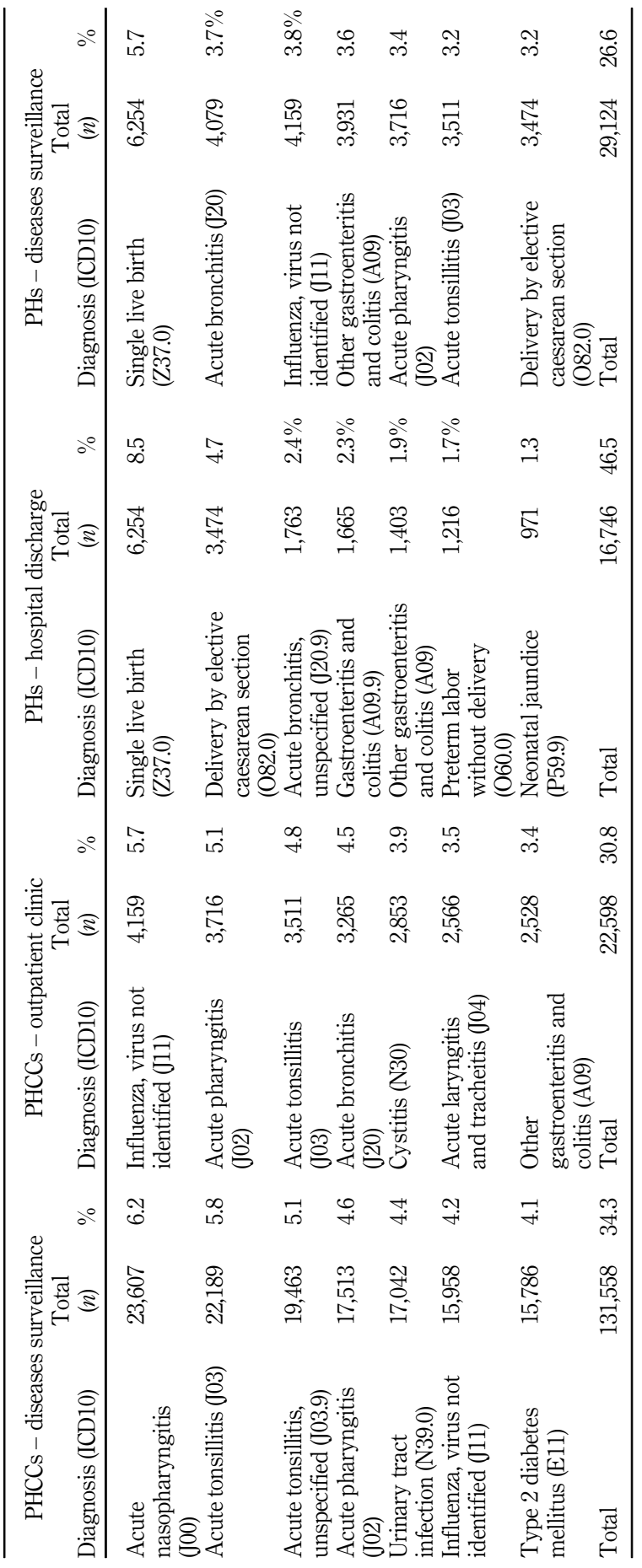

Table 2.

The seven most common MCHCS diagnoses (ICD-10 coded) in Duhok Province, 2020 
to decide on a shared strategy. Findings from the weekly checking of activities and feedback from local staff members were reported. Approval from the local health authorities was obtained for enrolling new health centers, meeting the MCHCS supervisors, retrieving data, training local staff members and sharing findings within the $\mathrm{PhD}$ research. The $\mathrm{PhD}$ students discussed the suggested implementation with the project manager, for better tailor different action plans to the needs of each facility.

\section{Training of local staff members}

Ongoing training on the importance of collecting reliable and accurate data were offered to health personnel. Overall, in the Duhok Province, 183 health operators involved in MCHCS (medical doctors, administrative staff members, nurses, statisticians, IT operators, pharmacists, public health specialists) have been trained.

\section{Monitoring and evaluation}

During daily data entry, health staff members were constantly supervised through field visits and online monitoring, in order to enable timely correction of possible mistakes. When field visits could not be performed, phone calls and communication groups were organized, resulting in a rapid question/answer mechanism.

\section{Discussion}

The transformation of raw data into evidence and health intelligence is paramount in guiding the formulation of public health policies [13], and in allocating resources to improve health and reduce inequalities [14]. As a matter of fact, there is a direct correlation between well-functioning registration, vital statistics systems and social and health development [15].

In Iraq, health facilities are facing several problems related to data, concerning mainly the use and management of paper-based records, which increase the possibility that essential information could be lost or misplaced. The Iraqi $\mathrm{MoH}$ has recently been endeavoring to employ e-health to support the country's healthcare sector. However, at present, little is known about the actual implementation plan [16]. The WHO is supporting initiatives in the Eastern Mediterranean region [17] to develop national health information systems so as to improve timely and comprehensive registration of health data [18, 19]. Since 2015, WHO has been implementing an Interactive Electronic Reporting System in Jordan [20], trying to integrate an e-health initiative launched in 2000 with the (still to be achieved) goal of connecting public hospitals in the country within three years [21].

In line with the WHO approach, the University of Rome Tor Vergata-Italy has been working with the KRI MoH since 2015 to implement the first integrated HIS in Iraqi Kurdistan, aimed at gathering public health data. At present, the KRG-HIS gathers information from 60 local health facilities, with more than one million collected events, making this e-health platform the most extensive sentinel surveillance system in the area [22]. The field-based research and the analysis related to the project have made it possible to identify gaps in performance and missing data, so as to develop tailored solutions.

Investing in local human resources is a key aspect of the project. Ongoing training of the staff members of each MCHCS facility is provided at all levels and stages, i.e. before activities start and on the job. A hotline has been set up (calls, messaging tools, online meetings) to enable rapid questions/answers and requests. The public health and engineering specialists trained under the $\mathrm{PhD}$ programs will guarantee the future continuity and sustainability of the e-health system created.

Maternal and child health data 
JHR

36,4

762
With the wider aim of supporting the development of a "culture of data for action" [23], seminars and practical training sessions are routinely conducted for local staff members and medical personal, through the establishment of a team of local experts.

To achieve all these targets, multiple stakeholder partnerships (academia, international cooperation, local health authorities) are essential. The KRG-HIS is starting to provide highquality data, which are needed for national and subnational planning, policy implementation and monitoring of health outcomes and services. The future aim, which is also the target of the $\mathrm{PhD}$ research, is to collect high-quality data so that the experience gained can be used to improve data collection and to produce reliable health information, thus becoming a valuable paradigm for Middle Eastern Regions.

\section{Conclusion}

Collaboration between academia and local health authorities has made it possible to integrate theory with field practice, tailoring actions to specific needs. A key aspect of the sustainability of such a project is the development of a culture of public health not only among the personnel who are managing the system but also among clinicians and health authorities. The scalingup of the KRG-HIS will provide updated statistics on MCHCS, supporting policymakers in evaluating strengths and weakness, so to implement actions aimed at improving mother and child health.

\section{Conflict of Interest: None}

\section{References}

1. Anthony CR, Moore M, Hilborne LH, Mulcahy AW. Health sector reform in the Kurdistan Region Iraq: financing reform, primary care, and patient safety. Rand Health Q. 2014; 4(3): 2.

2. International Organization for Migration [IOM]; United Nations Population Fund [UNFPA]; Kurdistan Regional Statistics Office [KRSO]. Demographic survey: Kurdistan region of Iraq. [updated 2018 Jul; cited XXX]. Available from: https://iraq.iom.int/files/KRSO_IOM_UNFPA_ Demographic_Survey_Kurdistan_Region_of_Iraq.pdf.

3. Shukor AR, Klazinga NS, Kringos DS. Primary care in an unstable security, humanitarian, economic and political context: the Kurdistan Region of Iraq. BMC Health Serv Res. 2017; 17(1): 592. doi: 10.1186/s12913-017-2501-z.

4. District health information software 2 (DHIS2). [cited 2020 October]. Available from: https://www. dhis2.org.

5. Gialloreti LE, Moramarco S, Palombi L. Investing in epidemiological surveillance for recovering health systems in war-torn countries. Perspect Public Health. 2020; 140(1): 25-6. doi: 10.1177/ 1757913919872514.

6. World Health Organization [WHO]. WHO guidelines on ethical issues in public health surveillance. Geneva: WHO; 2017.

7. World Health Organization [WHO]. Global health estimates 2016: deaths by cause, age, sex, by country and by region, 2000-2016. Geneva: WHO; 2018.

8. Asaad AM, Lami F, Khaleel HA, Assi WS, Ahmed W. Results of the rapid assessment of civil registration and vital statistics in Iraq. Can Stud Popul. 2020; 47(3): 183-93. doi: 10.1007/s42650020-00029-5.

9. Abramzon S, Burger N, Ghosh-Dastidar B, Glick P, Kumar KB, Perez-Arce F, et al. Capacity nuilding at the Kurdistan region statistics office through data collection. [updated 2014; cited 2020 October]. Available from: https://www.rand.org/pubs/research_reports/RR293.html.

10. Lopez AD, Setel PW. Better health intelligence: a new era for civil registration and vital statistics? BMC Med. 2015; 13: 73. doi: 10.1186/s12916-015-0333-4. 
11. Webster PC. Iraq's health system yet to heal from ravages of war. Lancet. 2011; 378(9794): 863-6. doi: 10.1016/s0140-6736(11)61399-8.

12. World Health Organization [WHO]. Health systems profile- Iraq. Regional health systems observatory- EMRO. [cited 2020 October]. Available from: http://digicollection.org/hss/documents/ s17295e/s17295e.pdf.

13. World Health Organization [WHO]. Everybody business: strengthening health systems to improve health outcomes: WHO's framework for action. Geneva: WHO; 2007.

14. World Health Organization [WHO]. Providing health intelligence to meet local needs: a practical guide to serving local and urban communities through public health observatories. Kobe: WHO; 2014.

15. Setel PW, Macfarlane SB, Szreter S, Mikkelsen L, Jha P, Stout S, et al. A scandal of invisibility: making everyone count by counting everyone. Lancet. 2007; 370(9598): 1569-77. doi: 10.1016/ S0140-6736(07)61307-5.

16. Jaber MM, Ghani MKA, Herman NS. A review of adoption of telemedicine in middle east countries: toward building Iraqi telemedicine framework. Sci Int (Lahore). 2014; 26(5): 1795-800.

17. World Health Organization [WHO]. Regional office for the Eastern Mediterranean. Regional strategy for the improvement of civil registration and vital statistics systems 2014-2019. [updated 2013; cited 2020 October]. Available from: https://apps.who.int/iris/handle/10665/123413.

18. Sahay S, Rashidian A, Doctor HV. Challenges and opportunities of using DHIS2 to strengthen health information systems in the Eastern Mediterranean region: a regional approach. Electron J Inf Syst Dev Ctries. 2020; 86(1): e12108. doi: 10.1002/isd2.12108.

19. Emberti Gialloreti L, Basa FB, Moramarco S, Salih AO, Alsilefanee HH, Qadir SA, et al. Supporting Iraqi Kurdistan health authorities in post-conflict recovery: the development of a health monitoring system. Front Public Health. 2020; 8: 7. doi: 10.3389/fpubh.2020.00007.

20. World Health Organization [WHO]. Regional Office for the Eastern Mediterranean. Health and well-being profile of the Eastern Mediterranean Region: an overview of the health situation in the Region and its countries in 2019. Cairo: WHO Regional Office for the Eastern Mediterranean; 2020.

21. Matar N, Alnabhan M. Evaluating E-Health services and patients requirements in Jordanian hospitals. Int Arab J e-Technol. 2014; 3(4): 250-7.

22. Rashidian A. Effective health information systems for delivering the Sustainable Development Goals and the universal health coverage agenda. East Mediterr Health J. 2019; 25(12): 849-51. doi: 10.26719/2019.25.12.849.

23. Moore M, Anthony CR, Lim YW, Jones SS, Overton A, Yoong JK. The future of health care in the Kurdistan Region - Iraq: toward an effective, high-quality system with an emphasis on primary care. Rand Health Q. 2014; 4(2): 1.

\section{Corresponding author}

Stefania Moramarco can be contacted at: stefania.moramarco@gmail.com
Maternal and child health data 